\title{
Saúde mental e gênero: $O$ perfil sociodemográfico de pacientes em um centro de atenção psicossocial
}

Ioneide de Oliveira Campos. Universidade de Brasília. Walter Massa Ramalho. Universidade de Brasília. Valeska Zanello. Universidade de Brasília.

\section{Resumo}

Os Centros de Atenção Psicossocial são considerados serviços de saúde mental inovadores no contexto das políticas públicas brasileiras. Objetivamos nesse estudo caracterizar, comparar e analisar o perfil sociodemográfico entre mulheres e homens de um CAPS II, com base na perspectiva de gênero. Estudo transversal, de abordagem quantiqualitativa, com produção de dados por análise de prontuários de mulheres e homens. Os resultados demonstraram significativa presença feminina nesse serviço e evidenciaram características comuns entre os sexos, como baixos níveis de renda e escolarização, além de ocupações predominantemente baseadas nas diferenças de gênero. Reforçam, ainda, as desigualdades sociais e a precariedade da categoria "trabalho" na vida dos usuários/as, bem como a necessidade de projetos que valorizem a economia solidária como alternativa de trabalho e geração de renda. Investimentos em políticas públicas transversais, especialmente na educação permanente de profissionais da equipe de saúde mental, em uma perspectiva de gênero, também se mostraram necessários.

Palavras-chave: saúde mental; mulheres; gênero; condições sociais.

\begin{abstract}
Mental and gender health: The sociodemographic profile of patients in psychosocial attention center. The Centers of PsychoSocial Attention (CAPSs) are considered innovative mental health services in the context of Brazilian public policies. This study describes, contrasts, and analyzes the socio-demographic profile of women and men receiving services in a CAPS II in Brasília, based on a gender studie's view. This cross-sectional study, supported by a quantitative, produced data for a analyzing the women and men's record. The Results showed significant presence of female receiving treatment in this service and exposed common characteristics among male and female users, such as low education and incoming level, and occupations mainly based on gender differences. These findings reinforce social inequalities and precariousness of work in the lives of users and display the need for projects that foster the solidarity economy as a source of employment and income. Investments in cross-sectional public policy, especially in training of mental health professionals in a gender oriented perspective, also proved necessary.
\end{abstract}

Keywords: mental health; women; gender; social conditions.

\section{Resumen}

Salud mental y género: El perfil sociodemográfico de pacientes en un centro de atención psicossocial. Los Centros de Atención Psicosocial son considerados servicios de salud mental innovador en el contexto de las políticas públicas brasileñas. Este estudio tuvo como objetivo caracterizar, comparar y analizar el perfil sociodemográfico de las mujeres y de los hombres de un CAPS II, con base en la perspectiva de género. Estudio transversal de enfoque cuantitativo y cualitativo, con producción de los datos por análisis de los prontuarios de las mujeres y los hombres, desde el protocolo de acogida. Los resultados mostraron presencia femenina significativa en este servicio y mostraron características comunes entre los sexos, como los bajos niveles de renta y de educación, además de las ocupaciones predominantemente basado en las diferencias de género. Refuerzan aún las desigualdades sociales y la precariedad de la categoría trabajo en la vida de los usuarios/as, así como la necesidad de proyectos que valoricen la economía solidaria como una fuente de empleo y generación de renta. Los investimentos en las políticas públicas transversales, sobre todo en la formación continuada de los profesionales del equipo de salud mental, en una perspectiva de género, también resultaron necesario.

Palabras-clave: salud mental; mujeres; género; condiciones sociales. 
As transformações das práticas e do paradigma psiquiátrico no contexto da saúde mental abriram um novo campo de possibilidades e de formulação de políticas de saúde mental (Alverga \& Dimenstein, 2006; Amarante, 1995; Devera \& Costa-Rosa, 2007; Tenório, 1994). Essas mudanças implicaram a construção de um modelo cuja característica central é o cuidado em saúde mental territorial, realizado também pelos Centros de Atenção Psicossocial (CAPS). Esses serviços inseridos na gestão pública de saúde são considerados a principal estratégia política e têm como desafio a desinstitucionalização (Rotelli, Leonardis, Mauri, \& Risio,1990).

A Política Nacional de Saúde Mental preconiza várias tipificações de CAPS: CAPS I, II e III; CAPS infantil; CAPS álcool e outras drogas (ad) e CAPS ad III. Esses centros ofertam diversos tipos de atividades terapêuticas intermediadas por uma equipe multiprofissional responsável por psicoterapia individual ou em grupo, acolhimento, oficinas terapêuticas, atividades comunitárias, atividades artísticas, orientação e acompanhamento do uso de medicação, atendimento domiciliar e aos familiares. De acordo como o Ministério da Saúde [MS] (2004), essas ações estão articuladas por projeto terapêutico singular e na perspectiva da reabilitação psicossocial.

Dentre as atividades terapêuticas, destaca-se o acolhimento aos usuários/as como um dos eixos importantes de cuidado nos CAPS. É diretriz da Política Nacional de Humanização (PNH) e pode ser realizado em dias não pré-determinados e por profissional não específico e especializado para executá-lo. Trata-se do primeiro contato do usuário com o serviço, momento em que lhe é explicado aquilo que é oferecido e o modo. Além disso, caracteriza-se como uma oportunidade para triar a demanda, ou seja, definir, após avaliação do profissional, se o caso é pertinente ao CAPS e, se não for, quais as possibilidades de atendimento na rede de serviços para essa pessoa.

Segundo Franco, Bueno e Merhy (1999), o acolhimento propõe inverter a lógica de organização e funcionamento do serviço de saúde, com base nos seguintes princípios: 1) atender a todas as pessoas que procuram os serviços de saúde, garantindo a acessibilidade universal; 2) reorganizar o processo de trabalho, deslocando o seu eixo do médico para uma equipe multiprofissional; 3) qualificar a relação trabalhador-usuário, com vistas a conferir parâmetros humanitários, de solidariedade e cidadania.

Dessa forma, o acolhimento deve ser visto como aspecto vital no processo de trabalho e garantia do acesso universal e resolutivo à população, princípios básicos do SUS. Portanto, segundo Schmidt e Figueiredo (2009), o acolhimento utilizado como técnica pela equipe interdisciplinar pode produzir capacidades de resposta ao usuário, à medida que a equipe multiprofissional considera a importância de superar a fragmentação dos saberes e buscar novas respostas às demandas emergentes das pessoas que procuram os serviços de saúde.

Atender as demandas emergentes dos usuários/as implica o reconhecimento pela equipe técnica do acolhimento como um ato de cuidado no campo da Saúde Mental, descrito como a essência do trabaIho no cotidiano (Yasui, 2007). Sugere, portanto, uma atitude de preocupação e envolvimento com o outro, o que representa uma ruptura do paradigma clínico tradicional baseado na relação mecânica causa-efeito na análise do adoecimento psíquico (Rotelli, 1990), para a busca incessante do novo paradigma, que contempla a adoção de um olhar para o contexto e os recursos dos usuários/as (Vasconcelos, 2013).

$\mathrm{Na}$ perspectiva do acolhimento, a realização de análises sociodemográficas, tendo os CAPS como cenário de pesquisas, pode melhor dimensionar a necessidade e o caráter das ações em saúde com base no conhecimento da demanda, não somente clínica, mas também das condições sociais daqueles que procuram por serviços de saúde mental. Essas análises envolvem variáveis complexas, principalmente quando associadas a políticas econômicas e sociais, renda, posses, situação de vida, ocupação e educação. No entanto, por não serem equivalentes, essas medidas podem ter distintos significados e representar conceitos diferentes de status social em culturas variadas (Araya, Lewis, Rojas, \& Fritsch, 2003). Além disso, quando estudadas em associação aos transtornos mentais comuns (TMC) cujos sintomas são insônia, fadiga, irritabilidade, esquecimento, dificuldades de concentração e queixas somáticas (Goldberg \& Huxley, 1992), demonstram os desdobramentos da desvantagem social, falta de bens materiais, baixa renda e dificuldades financeiras em países ocidentais.

Embora a ênfase deste artigo não seja nos sintomas dos TMC, observamos e destacamos que são os mais frequentemente relatados durante o 
momento de acolhimento, especialmente por mulheres usuárias do CAPS II de uma capital brasileira, cenário desta pesquisa. Destacamos que, diante da escassez de estudos sociodemográficos em CAPS II, para desenvolvimento deste estudo, objetivamos elaborar uma análise, na perspectiva de gênero e saúde mental, de dados sociodemográficos de homens e mulheres, com base nas informações de prontuários, especialmente do protocolo de entrevista inicial: a ficha de acolhimento de homens e mulheres.

\section{Metodologia}

Trata-se de um estudo transversal, quantiqualitativo (Creswell, 2010), baseado em prontuários de homens e mulheres atendidos no Centro de Atenção Psicossocial (CAPS II) de uma capital brasileira. Os dados sociodemográficos foram coletados a partir das fichas de acolhimento e anamnese psiquiátrica de todos os usuários/as admitidos entre os anos de 2012 e 2013, totalizando 234 prontuários, sendo 169 mulheres e 65 homens.

Como exclusão, foram adotados os seguintes critérios: usuários/as que não deram continuidade ao tratamento e cujas fichas de acolhimento e evolução psiquiátrica se encontravam no arquivo permanente do serviço; prontuários que apresentaram apenas a ficha de acolhimento e uma consulta do clínico geral do CAPS (geralmente de usuários/as que ainda irão passar pela avaliação psiquiátrica); usuários/as que, equivocadamente, encontravam-se no arquivo de ativos, porém não apresentavam anamnese psiquiátrica e evolução psiquiátrica, somente o registro do médico clínico geral desse serviço; e as fichas sem o correto preenchimento sociodemográfico.

Todas as fichas elegíveis de acolhimento e evoluções psiquiátricas da população foram escaneadas, utilizando um scanner portátil com base de mesa digitalizadora. As variáveis analisadas, presentes na ficha de acolhimento foram: faixa etária: em intervalos de 9 anos, a partir de 18 anos; estado civil: casado (a), solteiro (a), separado (a), viúvo (a). Consideramos ainda na situação conjugal, união estável como casado (a); religião: católica, protestante, espírita, outra, nenhuma e não consta; escolaridade: analfabeto, ensino fundamental, ensino médio, ensino superior, ensino especial e não consta; número de filhos: de um a seis, incluindo os itens "não tem" e "não consta"; renda familiar per capita mensal, definida como renda familiar total em salários mínimos, com as atualizações monetárias dos anos de 2012 e 2013; trabalho: afastado, desempregado, doméstico não remunerado, remunerado (formal), informal, não trabalha, outro e não consta; ocupação: dona de casa, estudante, profissões de nível médio, nível superior, outros e não consta; benefícios: aposentadoria, pensionista, auxílio-doença, Benefício de Prestação Continuada, outros, não recebe e não consta. Optamos por considerar a informação sociodemográfica da anamnese psiquiátrica após conferência de todas as fichas, por se tratar da última atualização.

Todas as fichas foram digitadas em um banco de dados Microsoft Access para posterior análise. Utilizou-se análise descritiva por meio de frequências absolutas e percentuais e teste $\chi^{2}$ para a comparação entre as categorias. O nível de significância foi de 95\%. Para a análise qualitativa dos dados, elaboramos um levantamento de temas recorrentes presentes nas fichas de acolhimento e evoluções psiquiátricas dos pacientes.

A pesquisa foi aprovada pelo Comitê de Ética em Pesquisa (CEP) do Instituto de Ciências Humanas (ICH) da Universidade de Brasília, por meio do Protocolo $n^{\circ}$ 692.165/2014.

\section{Resultados}

Foram coletadas fichas de um total de 234 usuários, sendo 169 mulheres (72,22\%) e 65 homens (27,77\%), admitidos entre os anos de 2012 e 2013 . A Tabela A1 descreve os totais e percentuais da faixa etária, situação conjugal, escolaridade, religião e quantitativo de filhos, segundo sexo. As categorias apresentadas nesta tabela foram significativamente diferentes.

A faixa etária entre 35 a 44 anos foi a que apresentou maior proporção, tanto para mulheres (34,3\%) quanto para homens $(29,2 \%)$, embora que a segunda classe com maior proporção tenha sido a imediatamente superior para as mulheres ( 45 a 54 anos) e a inferior para os homens (24 a 34 anos), levando a observação de tendência de maior idade para as mulheres quando comparada aos homens.

No que se refere à situação conjugal, ainda que observada maior proporção de mulheres casadas (37,3\%), quando comparada as demais categorias (solteira; separada e viúva), as diferenças entre elas 
não eram tão grandes quando comparadas com os homens na categoria solteiros $(58,5 \%)$, que representava mais da metade das observações.

Em relação à escolaridade, encontramos que $48,7 \%$ das pessoas eram analfabetas ou possuíam o ensino fundamental, sendo que, das mulheres, a proporção era de $46,1 \%$ e dos homens, 55,4\%. Apenas $8,5 \%$ das pessoas tinham ensino superior, sendo que das mulheres, esta proporção era de $8,9 \%$ e dos homens, 7,7\%.

Dos que declararam seguir uma religião, a protestante foi a que teve maior declaração, seguida pela católica. Porém, a grande parte das pessoas não declararam a sua religião, ou não tinham nenhuma religião ou mesmo outras que não estavam relacionadas.

A maior parte das mulheres eram mães, com poucos filhos, de um ou dois filhos (47,9\%), e apenas $18,3 \%$ delas declararam não ter filhos. Para os homens, a grande maioria declarou não ter filhos $(52,3 \%)$.

$\mathrm{Na}$ Tabela 1, todas as variáveis tiveram resultados significativos para o teste do qui-quadrado, tanto para as mulheres quanto para os homens, portanto as distribuições entre classes não foram aleatórias.

Sobre as variáveis "trabalho", "renda", "benefícios sociais e de saúde" e "ocupação", os dados indicam várias relações com a saúde mental (Tabela 2). A proporção de $58,6 \%$ das mulheres declararam trabaIhar em ambiente doméstico, de forma remunerada ou não, enquanto que $56,9 \%$ dos homens estavam desempregados ou não trabalhavam.

Descrição sobre a Renda Familiar foi marcada pela categoria "Sem informação", tanto para as mulheres $(56,8 \%)$ quanto para os homens $(50,8 \%)$. A maior parte, tanto dos homens, quanto para as mulheres, cujos prontuários continham esta informação, declarou estar situados em uma faixa de um a três salários mínimos.

Informações sobre Benefícios também foi semelhante à Renda, quanto à classe "Sem informação", mulheres, 58,6\% e homens 49,2\%. Nas mulheres predominou o "Auxílio-doença", com 17,2\%, enquanto que para os homens, "Não recebe" com $16,9 \%$.

No que se refere à ocupação, apontam que $31,4 \%$ de mulheres eram donas de casa, enquanto nenhum homem exercia essa função. Dentre os homens predominou a classe "Outros", com 55,4\%.

$\mathrm{Na}$ Tabela 2, todas as variáveis tiveram resultados significativos para o teste do qui-quadrado, à exceção da variável "Benefício" para os homens.

$\mathrm{Na}$ análise qualitativa dos principais temas recorrentes nos prontuários, emergiram as seguintes questões relacionadas à trajetória de vida, especialmente das mulheres: relações maternais aparecem como ruptura - depois de ter um filho ou depois de perder um filho, como também depois de briga com o filho ou envolvimento do filho com as drogas. Expressões como "dificuldades no cuidado com os filhos", "desejo de matar os filhos", "depressão pós-parto após o nascimento do primeiro filho", "pensamento de agressividade com a filha", "queixa de que os filhos não lhe dão atenção suficiente e não aceita que eles sejam independentes", "início dos sintomas após o falecimento da filha", dentre outras, foram recorrentes nos prontuários das mulheres. A relação com a mãe aparece em quase todos os prontuários das mulheres, ora como dor da perda (morte), ora como relação conflituosa.

Outra questão que parece contribuir para o sofrimento psíquico intenso das mulheres refere-se à conjugalidade, expressa como: "medo do ex-companheiro matá-la", "marido a encarcerava", "vontade de matar o marido", "queixa-se de solidão em relação ao marido", "sente-se abandonada e humilhada pelo marido", "afirma ficar com ele por causa dos filhos". Tais expressões confirmam a hipótese da relação entre conjugalidade e sofrimento. Por outro lado, nos prontuários dos homens aparecem muito pouco esses aspectos e as descrições das crises psíquicas parecem estreitamente relacionadas aos sintomas descritos pela CID 10 (Classificação Internacional de Doenças), da esquizofrenia. Poucos relatos sobre conflitos familiares, relação conjugal, relação com os filhos e com mãe. As mulheres aparecem nos prontuários dos homens como cuidadoras dos maridos que adoecem e/ou mães cuidadoras de seus filhos que enlouquecem.

Ainda, observamos que a variável "vida laboral prejudicada", aparece tanto em homens, como em mulheres. Notamos que o termo "sobrecargas" apareceu associado ao trabalho das mulheres no âmbito privado, como doméstica e ou cuidadora de pessoas doentes na família. 
Saúde mental e gênero: O perfil sociodemográfico de pacientes em um centro de atenção psicossocial

Tabela 1. Distribuição dos Totais e Percentuais da Faixa Etária, Situação Conjugal, Escolaridade, Religião e Quantitativo de Filhos, Segundo Sexo.

\begin{tabular}{|c|c|c|c|c|c|c|c|c|c|}
\hline \multirow{2}{*}{ Categorias } & \multicolumn{3}{|c|}{ Feminino } & \multicolumn{3}{|c|}{ Masculino } & \multicolumn{3}{|c|}{ Total } \\
\hline & $\mathrm{N}$ & (\%) & $\mathbf{p}$ & $\mathbf{N}$ & (\%) & $\mathbf{p}$ & $\mathbf{N}$ & (\%) & $\mathbf{p}$ \\
\hline Faixa etária (anos) & & & $<0,001$ & & & $<0,001$ & & & $<0,001$ \\
\hline $25-34$ & 24 & $14,2[8,9-19,5]$ & & 18 & $27,7[16,8-38,6]$ & & 39 & $16,7[11,9-21,5]$ & \\
\hline $35-44$ & 58 & $34,3[27,2-41,5]$ & & 19 & $29,2[18,2-40,3]$ & & 73 & $31,3[25,4-37,3]$ & \\
\hline $55-64$ & 29 & $17,2[11,5-22,8]$ & & 5 & $7,7[1,2-14,2]$ & & 36 & $15,5[10,8-20,1]$ & \\
\hline 65 e mais & 5 & $3[0,4-5,5]$ & & 1 & $1,5[0-4,5]$ & & 7 & $3[0,8-5,2]$ & \\
\hline Situação conjugal & & & $<0,001$ & & & $<0,001$ & & & $<0,001$ \\
\hline Solteiro (a) & 45 & $26,6[20-33,3]$ & & 38 & $58,5[46,5-70,4]$ & & 83 & $35,5[29,3-41,6]$ & \\
\hline Casado (a) & 63 & $37,3[30-44,6]$ & & 18 & $27,7[16,8-38,6]$ & & 81 & $34,6[28,5-40,7]$ & \\
\hline Analfabeto (a) & 8 & $4,7[1,5-7,9]$ & & 6 & $9,2[2,2-16,3]$ & & 14 & $6,0[2,9-9,0]$ & \\
\hline Ensino Fundamental & 70 & $41,4[34-48,8]$ & & 30 & $46,2[34-58,3]$ & & 100 & $42,7[36,4-49,1]$ & \\
\hline Ensino médio & 70 & $41,4[34-48,8]$ & & 20 & $30,8[19,5-42]$ & & 90 & $38,5[32,2-44,7]$ & \\
\hline Ensino superior & 15 & $8,9[4,6-13,2]$ & & 5 & $7,7[1,2-14,2]$ & & 20 & $8,5[5,0-12,1]$ & \\
\hline Sem informação/outros & 6 & $3,6[0,8-6,3]$ & & 4 & $6,2[0,3-12]$ & & 10 & $4,3[1,7-6,9]$ & \\
\hline Religião & & & $<0,001$ & & & $<0,001$ & & & $<0,001$ \\
\hline Católica & 27 & $16,0[10,5-21,5]$ & & 10 & $15,4[6,6-24,2]$ & & 37 & $15,8[11,1-20,5]$ & \\
\hline Protestante & 44 & $26,0[19,4-32,7]$ & & 14 & $21,5[11,5-31,5]$ & & 58 & $24,8[19,3-30,3]$ & \\
\hline 3 filhos & 33 & $19,5[13,6-25,5]$ & & 5 & $7,7[1,2-14,2]$ & & 38 & $16,2[11,5-21]$ & \\
\hline 4 e mais filhos & 18 & $10,7[6-15,3]$ & & 5 & $7,7[1,2-14,2]$ & & 23 & $9,8[6-13,6]$ & \\
\hline Sem informação & 6 & $3,6[0,8-6,3]$ & & 4 & $6,2[0,3-12]$ & & 10 & $4,3[1,7-6,9]$ & \\
\hline
\end{tabular}

Fonte: elaboração dos autores, segundo dados constantes em prontuários dos usuários do Centro de Atenção Psicossocial II (CAPS II) do Distrito Federal, 2012 e 2013.

\section{Discussão}

Estudos brasileiros constatam que as mulheres são mais frequentadoras dos serviços públicos de saúde do que os homens (Filho, Chagas, Pinheiro, Lima, \& Durão, 2011; Travassos,Viacava, Pinheiro, \& Brito, 2002). Para Gomes, Nascimento e Araújo (2007), essa diferença associa a pouca procura por serviços de saúde por parte de homens a um modelo hegemônico de masculinidade, relacionado a hábitos de prevenção que usualmente são mais associados às mulheres, ao cuidado de si como expressão da esfera feminina, a relação do ser homem à invulnerabilidade, força e virilidade; a vergonha de ficar exposto ao profissional de saúde; o medo de descobrir que sua saúde está vulnerável; além da falta de unidades de saúde específicas para acolhimento das demandas dos homens.

Especificamente, sugere-se que a baixa demanda dos homens, no cenário desta pesquisa, pode estar relacionada ao modelo de masculinidade citado acima, nos quesitos "cuidado de si" e "medo de descobertas ruins sobre a sua saúde mental" (Gomes et al., 2007), os quais mascaram o sofrimento psíquico e dificultam o acesso a esse CAPS. Alguns protocolos de acolhimento e 
Tabela 2. Distribuição dos Totais e Percentuais da Situação de Trabalho, Renda Familiar, Benefícios e Ocupação, Segundo Sexo.

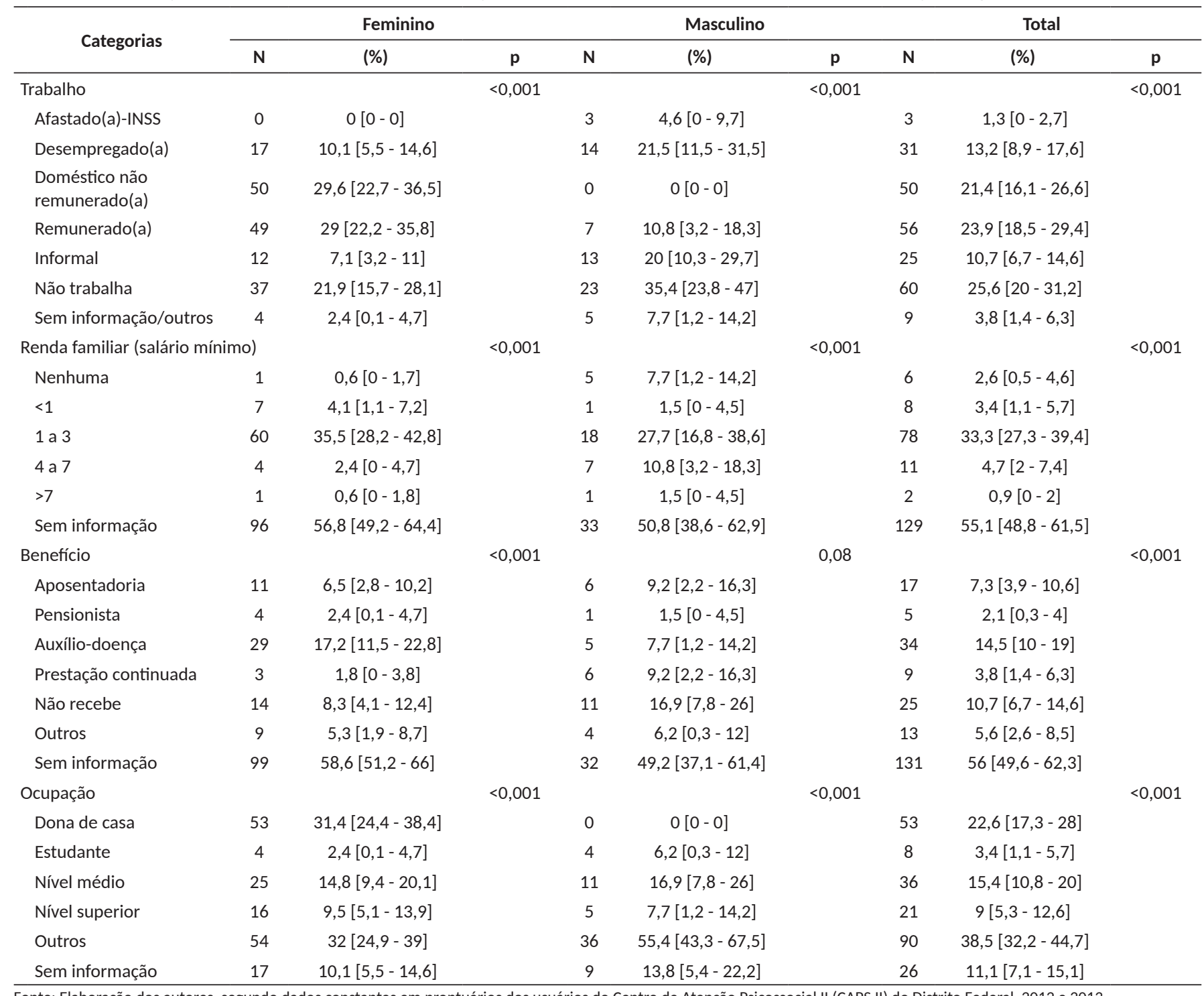

Fonte: Elaboração dos autores, segundo dados constantes em prontuários dos usuários do Centro de Atenção Psicossocial II (CAPS II) do Distrito Federal, 2012 e 2013.

evoluções psiquiátricas confirmam a existência da negação da doença pelo usuário e uso irregular da medicação, o que expressa a dificuldade de cuidar de si. Nesse sentido, um deles chamou atenção, por trazer a informação de o início dos sintomas ter sido há mais de 20 anos, mas o paciente ter procurado o CAPS apenas em 2001.

Já o alto percentual de mulheres adoecidas e frequentadoras desse CAPS pode apontar para uma questão importante de saúde pública, a psiquiatrização das mulheres. Muitas das condições citadas por elas foram expressas nos prontuários, em sua maioria conflitos com a mãe (desentendimentos, perdas e maus tratos) e parcela menor com o pai, além de conflitos relacionados à maternidade (crises após nascimento ou morte de um filho), relações conjugais (divórcio, separação, brigas, tentativas de suicídio, entre outros), diversos tipos de violências sofridas, vida laboral prejudicada e o papel de cuidadoras de outros e da casa.

Todas essas temáticas remetem a uma implosão de sofrimentos, em que a mulher "deixa de procurar a razão de seu mal-estar nas suas condições de existência e revela, por meio do sofrimento (situação de surto), a opressão interior e a perda de qualquer poder sobre si mesma" (Garcia, 1995, p. 119). Dessa maneira, há uma ontologização biomédica dos aspectos sociais e subjetivos dessas mulheres (Zanello, 2014a), sendo esse CAPS, um espaço de expressão das subjetividades femininas. 
Saúde mental e gênero: O perfil sociodemográfico de pacientes em um centro de atenção psicossocial

Importante ressaltar, nesta pesquisa, a proporção expressiva de mulheres casadas e separadas em comparação aos homens. No caso deles, destaca-se o estado civil "solteiro", dado que já foi confirmado, em outras pesquisas, como fator de risco para a saúde mental masculina (Windmöller \& Zanello, 2016). Já as mulheres, em idade madura, apresentaram histórias atuais ou recentes registradas em prontuários, em relação à conjugalidade e sofrimento, expressas nas seguintes situações: tentativas de suicídio quando residia com marido ou após o término do casamento; internação, inapetência e choro por acreditar ser traída pelo marido; início das alucinações auditivas após a separação; medo do ex-cônjuge matá-la; desejo de matá-lo; queixa de solidão, abandono e humilhação em relação ao marido; tentativa de matar o cônjuge após descoberta de existência de filha anterior ao casamento; sensação de atrapalhar a vida do companheiro; traição do marido; violência física e psicológica; descoberta sobre a homoafetividade do parceiro; incômodo nas relações sexuais; ideação suicida quando pensa no casamento e desejo de abandonar os filhos; e envolvimento do marido com a mãe da usuária, com consequente nascimento de uma criança que é irmã da usuária. São situações variadas e particulares, que enunciam diversas formas de violências.

Segundo Schaiber, D'Oliveira, Falcão e Figueiredo (2005), as violências têm uma repercussão importante na saúde, sendo estas repercussões abordadas no interior dos serviços que, ao mesmo tempo que acolhem os efeitos, tornam sua causa invisível, especialmente aqueles que fazem os diagnósticos, pois terminam por esgotar sua intervenção nesse plano, em que a violência é mascarada por sinais e sintomas. Alguns pesquisadores ressaltaram a dificuldade de tornar a violência contra a mulher um aspecto visível em Centro de Atenção Psicossocial (Pedrosa \& Zanello, 2016), pois além de não haver protocolos específicos que definam procedimentos para estes casos (Barbosa, Dimenstein, \& Leite, 2014), ou seja, além de não ser notificada, não é entendida como fator configurador dos próprios transtornos diagnosticados nas mulheres (Zanello, 2014b).

Destaca-se que quase $50 \%$ da população estudada era analfabeta ou com baixo nível de escolaridade (tanto homens quanto mulheres). Em uma sociedade letrada, a escolaridade desponta como uma possibilidade importante de empoderamento e mobilidade social. Como já sublinhado por vários autores (Kleinman, 1991; Littlewwod, 2002), quadros "psiquiátricos" muitas vezes mascaram sofrimentos de sujeitos que se encontram em lugares de maior vulnerabilidade social. Seria profícuo que mais estudos fossem realizados para aprofundar o impacto dessa marginalização e seus desdobramentos na vida dessas pessoas, bem como na configuração de seus sofrimentos.

Sobre a variável trabalho, um dado significativo diz respeito às donas de casa e ao trabalho doméstico. Para Hirata e Kergoat (2007), este trabalho é "efetuado gratuitamente pelas mulheres, é invisível e realizado não para elas mesmas, mas para outros, e sempre em nome da natureza, do amor e do dever materno" (p. 3). Segundo as autoras, trata-se de um ponto importante de discussão acerca da divisão sexual do trabalho, pois, apesar das mudanças sociais e a entrada da mulher no mundo público (assalariado), a atribuição a elas do trabalho doméstico continuou intacta e lenta (Hirata \& Kergoat, 2007, 2002; Perrot, 2013).

No Brasil a situação não é diferente. Segundo o IBGE (2012), 94,85\% das mulheres exercem dupla jornada (trabalham fora e dentro de casa), contra somente $5,2 \%$ dos homens. O IBGE aponta ainda que a média de horas semanais gastas com trabalho doméstico para as mulheres é de $27,7 \mathrm{~h}$, enquanto homens trabalham apenas 11,2h. Há, assim, uma sobrecarga de atribuições e trabalho invisível e não legitimado, o que pode favorecer o adoecimento psíquico (Santos, 2014).

Também encontramos diferenças perceptíveis na classificação "outros". Essa classificação abrange ocupações que agregam pouco valor social para ambos os sexos. No que concerne às mulheres, os empregos de menor qualidade a ela reservados foram aqueles que ainda mantêm um caráter doméstico: "auxiliar de limpeza", "auxiliar de serviços gerais", "auxiliar de supermercado", "babá", "diarista", "costureira", "cozinheira", "lavadeira", "passadeira" e "doceira". Por outro lado, também exerciam atividades consideradas masculinas: "frentista", "despachante", "porteira" e "manutenção de aeronaves em aeroportos". Para os homens, prevaleceram ocupações tipicamente masculinas: "auxiliar em construção civil", "bicheiro", "auxiliar de depósito", "auxiliar em oficina mecânica", "porteiro", "lavrador", "marceneiro", "marinheiro", "pintura em carros", "vigilante", entre outros. Essa classificação reafirma a forma particular da divisão social do trabalho e seu princípio organizador, o de separação, que pressupõe que existem trabalhos de homens e trabalhos de mulheres (Hirata \& Kergoat, 2007). 
Nas ocupações classificadas como de nível superior, percentual maior foi encontrado para as mulheres, em relação aos homens, com predomínio de professoras. Em alguns prontuários, era citado o termo "cuidadora" relacionado ao trabalho doméstico de quem cuida de pessoas doentes na família, o que gera sobrecarga, cansaço e exaustão.

Quanto à situação de trabalho, os dados ainda mostram um percentual alto de mulheres e de homens que não trabalham. Esses dados nos permite inferir que, no geral, estas pessoas encontram-se nas seguintes situações: à espera da aprovação de benefícios sociais/ saúde e ou dependência financeira do marido, esposa ou família. A proporção de homens desempregados superou a de mulheres, dado que pode estar associado à gravidade clínica e incapacitante desses usuários, isto é, os homens diagnosticados com esquizofrenia, transtornos esquizotípicos e delirantes. Dessa forma, nesse CAPS, encontramos também maior número de mulheres no mercado de trabalho, em comparação aos homens.

Além disso, evidenciamos também maior percentual de homens que exercem atividades informais. O trabalho informal apresenta risco para a saúde mental de jovens (Santana, Newman, \& Harlowet, 1997). Esse risco relaciona-se à instabilidade, condições ruins de trabalho, baixos salários, jornada excessiva de trabalho, ausência de benefícios sociais e de proteção da legislação trabalhista, no entanto seu impacto parece ser maior sobre as mulheres (Ludemir, 2000, 2005).

No que concerne à renda familiar, os salários mais altos foram observados entre homens; e sobre os benefícios sociais e de saúde, encontramos que as mulheres recebem mais benefícios que os homens, embora as diferenças não tenham sido significativas pela ausência de dados nos prontuários.

Os resultados sobre ocupação, situação de trabaIho, renda familiar e benefícios explicitam a desvalorização social e a precariedade do trabalho na atenção psicossocial (Saraceno, 2001), inseridos em um modelo de desenvolvimento social e econômico desigual. Para Martins (2002), esse modelo, em suas consequências sociais adversas, "leva simultaneamente a extremos de progresso tecnológico e de bem-estar para setores limitados da sociedade e a extremos de privação, pobreza e marginalização social para outros setores da população" (p. 13). Para atenuar tantos efeitos prejudiciais, Martins (2002) aponta que a alternativa tem sido as políticas sociais compensatórias, necessárias nessa circunstância, apesar de confirmarem e legitimarem a exclusão social, aqui entendida não somente como pobreza, mas problema social procedente da vivência real de experiências dolorosas cotidianas de privações, de limitações e anulações.

Por fim, é importante mencionar que, ao longo desse estudo, emergiram dificuldades para esse levantamento sociodemográfico, sobretudo decorrentes de letras ilegíveis, dados incompletos e vários campos sem preenchimento (renda familiar, ocupação, benefícios sociais e/ou de saúde recebidos e exame psíquico), o que limitou os achados e o aprofundamento das análises estatísticas. Como mencionado, foi possível detectar, em muitos prontuários, informações divergentes entre ficha de acolhimento e anamnese psiquiátrica, por exemplo, nas variáveis "escolaridade", "ocupação" e "religião". Nesses casos, recorremos à primeira anamnese psiquiátrica, a fim de atualizar a informação sobre o usuário/a. Inexistiram, todavia, informações sobre etnia e raça nos prontuários consultados e, especificamente, em algumas anamneses psiquiátricas foi possível observar a inexistência de dados, como idade, escolaridade, número de filhos, ocupação e religião.

No entanto, essas variáveis mencionadas são relevantes para a análise das condições de vida das pessoas que procuram os serviços de saúde mental. Além disso, evidências indicam que fatores socioculturais contribuem para a compreensão "das diferenças entre os gêneros em saúde e saúde mental" (Shearm, Halmi, Widiger, \& Boyce, 2008, p. 63), assim como para o entendimento da vulnerabilidade social dos sujeitos com uma maior ou menor inserção no mundo do trabaIho e/ou relacional (Castel, 1994). Ou seja, faz-se importante a compreensão das "variáveis reais que mudam as vidas reais das pessoas reais", relacionadas aos sujeitos, contextos, serviços e recursos (Saraceno, 2001, p. 83).

\section{Considerações finais}

Os resultados delinearam características sociodemográficas, sobretudo para as mulheres, apontadas pela literatura como fatores de risco à saúde mental, tais como: pobreza, condições de vida (econômica, mas também conjugal/familiar), trabalho precário e exclusão social.

No entanto, consideramos que a limitação/ ausência de dados nas fichas de acolhimento nos leva ao entendimento de que a maioria dos profissionais apresentam dificuldades em considerar determinados aspectos da vida do usuário/a significativos para a compreensão do sofrimento psíquico. Persistem ações 
enviesadas e sujeitos "perdidos" no anonimato, na invisibilidade subjetiva, desprovidos de história individual e coletiva, como menciona Basaglia (1987), o que só reafirma o paradigma biológico em detrimento de práticas sociais e de saúde voltadas ao desenvolvimento de oportunidades e subsídios existentes.

As ações, de fato, de educação permanente, atreladas às políticas públicas de saúde mental, podem contribuir para qualificar essas práticas, no sentido de construir uma escuta de gênero afinada e sensível e, assim, garantir o acolhimento das demandas de mulheres e homens, em uma perspectiva de compreensão dos processos sociais integrados ao cotidiano das pessoas em sofrimento psíquico.

Fomentar as discussões sobre os investimentos em projetos de trabalho e geração de renda, assim como o desenvolvimento de políticas públicas específicas baseadas na interface de gênero e saúde mental, pode contribuir para experiências de trabalho diversificadas, tendo como pressuposto a inclusão social.

\section{Referências}

Alverga, A. R., \& Dimenstein, M. (2006). A reforma psiquiátrica e os desafios na desinstitucionalização da loucura. Interface, 10(20), 299-316. doi: 10.1590/S1414-32832006000200003

Amarante, P. (1995). Novos sujeitos, novos direitos: o debate em torno da reforma psiquiátrica. Cadernos de Saúde Pública, 11(3), 491494. doi: 10.1590/S0102-311X1995000300024

Araya, R., Lewis, G., Rojas, G., \& Fritsch, R. (2003). Education and income: which is more important for mental health? Journal of Epidemiology Community Health, 57(7), 501-505. doi: 10.1136/ jech.57.7.501

Basaglia, F. (1987). Mujer, Locura y Sociedad. México: Universidad Autónoma de Puebla.

Barbosa, L. B., Dimenstein, M., \& Leite, J. F. (2014). Mulheres, violência e atenção em saúde mental: questões para (re) pensar o acolhimento no cotidiano dos serviços. Avances en Psicología Latinoamericana, 32(2), 309-320. doi: dx.doi.org/10.12804/ apl32.2.2014.09

Brasil, Ministério da Saúde, Secretaria de Atenção à Saúde, Departamento de Ações Programáticas Estratégicas (2004). Saúde mental no SUS: os centros de atenção psicossocial. Recuperado de http://www.ccs.saude.gov.br/saude_mental/pdf/sm_sus.pdf

Castel, R. (1994). Da indigência à exclusão, a desfiliação. Precariedade do trabalho e vulnerabilidade relacional. In A. Lancetti (Org.), Saúde loucura (pp. 21-48). São Paulo: Hucitec.

Creswell, J. W.(2010). Projeto de pesquisa: métodos qualitativo, quantitativo e misto. Porto Alegre: Artmed.

Devera, D., \& Costa-Rosa, A. (2007). Marcos históricos da Reforma Psiquiátrica Brasileira: transformações na legislação, na ideologia e na práxis. Revista de Psicologia da UNESP, 6(1), 60-79. Recuperado de http://www2.assis.unesp.br/revpsico/index.php/ revista/article/viewFile/46/88
Filho, P. C. P.T., Chagas, A. R., Pinheiro, M. L. P., Lima, A. M. J., \& Durão, A. M. S. (2011). Utilização de benzodiazepínicos por idosos de uma estratégia de saúde da família: implicações para enfermagem. Escola Anna Nery, 15(3), 581-586. Recuperado de http://www. revistaenfermagem.eean.edu.br/detalhe_artigo.asp?id=682

Franco, T. B., Bueno,W. S., \& Merhy, E. E. (1999). O acolhimento e os processos de trabalho em saúde: Betim, Minas Gerais, Brasil. Cadernos de Saúde Pública, 15(2), 345-53. Recuperado de http:// www.scielo.br/pdf/csp/v15n2/0319.pdf

Garcia, C. C. (1995). Ovelhas na névoa: um estudo sobre as mulheres e a loucura. Rio de Janeiro: Record; Rosa dos Tempos.

Goldberg, D., \& Huxley, P. (1992). Common mental disorders: a bio-social model. Londres: Tavistock.

Gomes, R., Nascimento, E. F., \& Araújo, F. C. (2007). Por que os homens buscam menos os serviços de saúde do que as mulheres? As explicações de homens com baixa escolaridade e homens com ensino superior. Cadernos de Saúde Pública, 23( 3), 565-574, doi:10.1590/ S0102-311X2007000300015

Hirata, H., \& Kergoat, D. (2007). Novas configurações da divisão sexual do trabalho. Cadernos de Pesquisa (online), 37(132), 595-609. doi: 10.1590/S0100-15742007000300005

Instituto Brasileiro de Geografia e Estatística (2012). Pesquisa mensal de emprego. Recuperado de http://www.ibge.gov.br/home/ estatistica/indicadores/trabalhoerendimento/pme_nova/Mulher_ Mercado_Trabalho_Perg_Resp_2012.pdf

Kleinman, A. (1991). Rethinking psychiatry: from cultural category to personal experience. Nova lorque: Free Press

Littlewood, R. (2002). Pathologiesofthe West. An Anthropology of Mental IIIness in Europe and America. Ithaca, NY: Cornell University Press.

Ludermir, A. B. (2000). Inserção produtiva, gênero e saúde mental. Cadernos de Saúde Pública, 16( 3), 647-659. doi:10.1590/ S0102-311X2000000300013

Ludermir, A. B. (2005). Associação dos transtornos mentais comuns com a informalidade das relações de trabalho. Jornal Brasileiro de Psiquiatria, 54(2), 198-204. Recuperado de http://www.saudeetrabalho.com.br/download/informal-ludermir.pdf

Martins, J. S. (2002). A sociedade vista do abismo: novos estudos sobre a exclusão, pobreza e classes sociais. Rio de Janeiro: Vozes.

Pedrosa, M., \& Zanello, V. (2016). (In)visibilidade da violência contra as mulheres no serviço de saúde mental. Psicologia: Teoria e Pesquisa, 32(n. esp), e32ne214. doi: 10.1590/0102-3772e32ne214

Perrot, M. (2013). Minha história das mulheres. São Paulo: Contexto.

Rotelli, F. (1990). A instituição inventada. Revista Per lasalutementale/ For mental health, 1( 88), 89-99. Recuperado de http://www.oriundi. net/files/istituz.invent_po.pdf

Rotelli, F., Leonardis, O., Mauri, D., \& Risio, C. (1990). Desinstitucionalização, uma outra via. In F. Nicácio (Org.), Desinstitucionalização (pp. 17-59). São Paulo: Hucitec

Santana, V. S., Loomis, D., Newman, B., \& Harlowet, S. D. (1997). Informal jobs: another occupational hazard for woman's mental health. International Journal of Epidemiology, 26 (6), 1236-1242. Recuperado de http://ije.oxfordjournals.org/content/26/6/1236. full.pdf

Santos, L. S. (2014). Donas de casa, donas da própria vida? Problematizações acerca do trabalho (in)visível e da saúde mental de mulheres (des)valorizadas (Tese de Doutorado). Recuperado de http://repositorio.unb.br/handle/10482/18355 
Saraceno, B. (2001). Libertando identidades: da reabilitação psicossocial a cidadania possível. Belo Horizonte: Te Cora.

Schaiber, L. B., D'Oliveira, A. F. P. L., Falcão, M. T. C., \& Figueiredo, W.S (2005). Violência dói e não é direito: a violência contra a mulher, a saúde e os direitos humanos. São Paulo: Unesp

Schmidt, M. B., \& Figueiredo, A. C. (2009). Acesso, acolhimento e acompanhamento: três desafios para o cotidiano da clínica em saúde mental. Revista Latinoamericana de Psicopatologia Fundamental, 12(1), 130-140. doi:10.1590/S1415-47142009000100009

Shearm, K., Halmi, K. A., Widiger, T.. A., \& Boyce, C. (2008). Gênero e fatores socioculturais. In D. Regier; W. Narrow; M. First, \& P. Sirovatka. Gênero e idade: considerações no Diagnóstico Psiquiátrico (pp. 124-134). São Paulo: Roca.

Tenório, F. (1994). A Reforma Psiquiátrica Brasileira, da década de 1980 aos dias atuais: história e conceitos. História, Ciências, Saúde - Manguinhos, 1(1), 25-59. Recuperado de http://www.scielo.br/pdf/ hcsm/v9n1/a03v9n1.pdf

Travassos, C., Viacava, F.; Pinheiro, R., \& Brito, A. (2002). Utilização dos serviços de saúde no Brasil: gênero, características familiares e condição social. Revista Panamericana de Salud Publica, 11(5/6), 365-373. doi: 10.1590/S1020-49892002000500011
Vasconcelos, M. J. E. (2013). Pensamento sistêmico: o novo paradigma da ciência. Campinas, SP: Papirus.

Windmöller, N.; \& Zanello, V. (2016). Depressão e masculinidades: uma revisão sistemática da literatura em periódicos brasileiros. Psicologia em Estudo (Online), 21, 437-449. doi: 10.4025/psicolestud.v21i3.31896

Yasui, S. (2007). CAPS: estratégia de produção de cuidado e de bons encontros. In R. Pinheiro, A. P. Guljor, G. S. Junior, \& R. A. Mattos(Orgs.), Desinstitucionalização da Saúde Mental: contribuições para estudos avaliativos (pp. 155-167). Rio de Janeiro: CEPESC - IMS/UERJ - ABRASCO.

Zanello, V. (2014a). A saúde mental sob viés de gênero: uma releitura gendrada da epidemiologia, da semiologia e da interpretação e da diagnóstica. In V. Zanello \& A. P. M. Andrade (Orgs.), Saúde mental e gênero: diálogos, práticas e interdisciplinaridade (pp. 41-58). Curitiba: Appris.

Zanello, V. (2014b). Saúde mental, mulheres e conjugalidade. In C. Stevens, S. Oliveira; \& V. Zanello (Orgs.), Estudos Feministas e de Gênero: articulações e perspectivas (Vol. 1, pp. 108-118). Florianópolis: Mulheres

Ioneide de Oliveira Campos, Doutora em Psicologia Clínica e Cultura, é Professora Adjunta da Universidade de Brasília (UnB), Campus Ceilândia. Endereço para correspondência: Quadra 201, lote 4/11, apto 603, bloco E, residencial imprensa 1, Águas Claras, CEP 71.937-540, Brasília- DF. E-mail: ioncampos@hotmail.com

Walter Massa Ramalho, Doutor em Medicina Tropical, concentração em Epidemiologia no Programa de Pós-graduação em Medicina Tropical da Universidade de Brasília (UnB), é Professor Adjunto da Universidade de Brasília (UnB), Campus Ceilândia e Campus Darcy Ribeiro. E-mail: walter.ramalho@gmail.com

Valeska Zanello, Pós-doutorado pela Universidade Estadual Paulista (UNESP), Doutorado pela Universidade de Brasília (UnB)/Université Catholique de Louvain (UCL), Bélgica, é Professora Adjunta da Universidade de Brasília (UnB). E-mail: valeskazanello@uol.com.br

Recebido em 14.Out.15 Revisado em 16.Jan.17 Aceito em 03.Fev.17 